\title{
ANÁLISE DA PERCEPÇÃO AMBIENTAL E SENSIBILIZAÇÃO DE EDUCANDOS DO ENSINO FUNDAMENTAL DE UMA ESCOLA PÚBLICA PARA REALIZAÇÃO DA COLETA SELETIVA, CAMPINA GRANDE - PB
}

\author{
Livia Poliana Santana Cavalcante ${ }^{1}$, Larissa Santana Cavalcante ${ }^{2}$, Valbério Sales de Medeiros ${ }^{3}$, \\ Herika Juliana Linhares Maia ${ }^{4}$, Layana Dantas de Alencar ${ }^{5}$ \\ ${ }^{1}$ livia poliana@hotmail.com, ${ }^{2}$ fraularissa@hotmail.com, ${ }^{3}$ valberio@gmail.com, \\ herikajuliana@hotmail.com, ${ }^{5}$ layana dantas@yahoo.com.br
}

\section{RESUMO}

Este trabalho teve como objetivo analisar a disposição dos resíduos sólidos gerados na Escola de Ensino Fundamental Nossa Senhora do Rosário e a conscientização ambiental entre os alunos da Educação de Jovens e Adultos (EJA) em relação ao problema dos Resíduos Sólidos. A unidade de ensino foi selecionada em decorrência de sua localização e pelo fato da mesma já dispor dos coletores para a realização da coleta seletiva nas respectivas cores: amarelo, verde, vermelho e azul, porém estes se encontravam ociosos no pátio da escola já que a separação dos resíduos sólidos não estava ocorrendo de forma satisfatória, fato que remete ao entendimento de que os educandos, educadores e funcionários da unidade escolar provavelmente não conheciam e/ou não estavam sensíveis da importância da coleta seletiva. Após a análise dos dados obtidos e a verificação da falta de gerenciamento dos resíduos na unidade de ensino, foi promovido momentos de sensibilização, como palestras e oficinas sobre a problemática dos resíduos sólidos, no intuito dos educandos, educadores e funcionários conhecerem a diferença entre lixo e resíduos sólidos, lixão e aterro sanitário, enfocando a importância da coleta seletiva e o trabalho dos catadores de materiais recicláveis para a diminuição da poluição do meio ambiente e a redução da extração dos recursos naturais, como também geração de renda.

Palavras-chave: Coleta seletiva, Educandos, Educação de Jovens e Adultos, Percepção, Resíduos sólidos.

\section{ABSTRACT}

This study aimed to analyze the disposal of solid waste generated in the Elementary School Our Lady of the Rosary and environmental awareness among students of Youth and Adults (EJA) in relation to the problem of Solid Waste. The teaching unit was selected because of its location and the fact that it has available to collectors for the implementation of selective collection in their respective colors: yellow, green, red and blue, but they were stranded in the schoolyard as the separation of solid waste was not occurring in a satisfactory manner, a fact that leads to the understanding that students, educators and employees of the school unit probably did not know and / or were not sensitive to the importance of the collection. After data analysis and verification of the lack of waste management in the teaching unit, was promoted moments of awareness, such as lectures and workshops on the issue of solid waste, in order for students, educators and employees know the difference between trash and solid waste, landfill and landfill, emphasizing the importance of selective collection and the work of collectors of recyclable materials to reduce pollution of the environment and reduction of natural resource extraction, as well as income generation.

Keywords: Selective collection, Students, Youth and Adults, Perception, solid wastes. 


\section{INTRODUÇÃO}

Nos últimos anos o ser humano tem agido de forma a degradar cada vez mais o ambiente em que está inserido, contribuindo assim para a crise ambiental, onde um dos seus principais agravantes é a produção desenfreada de resíduos sólidos, decorrentes do crescimento populacional e industrial, o que compromete a capacidade de suporte dos sistemas naturais e antrópicos.

Sendo assim os problemas ambientais é gerado a partir da visão antropocêntrica do homem, este possui uma percepção de que o ser humano é superior aos demais elementos da natureza. Para Capra (1996) os problemas precisam ser vistos como diferentes facetas de uma única crise, crise de percepção.

No entender de Silva e Leite (2000) para a realização dos processos de educação, planejamento e gerenciamento voltados para as questões ambientais é importante conhecer a percepção ambiental dos indivíduos envolvidos. Esse conhecimento facilita a compreensão das interpelações do ser humano no meio ambiente.

Neste contexto, a Educação Ambiental é uma importante ferramenta para reverter esse quadro, porque permite a compreensão da complexidade do meio ambiente e o reconhecimento da interdependência e inter-relações existentes entre os seus diversos elementos, com vistas à utilização racional dos recursos naturais através de processos de sensibilização a partir da percepção ambiental do grupo envolvido.

A reciclagem e/ou reutilização de resíduos sólidos estão sendo vistas como duas importantes alternativas para a redução de quantidade de lixo no futuro, criando com isso bons hábitos de preservação do meio ambiente, o que nos leva a economizar matéria-prima e energia.

Para que ocorra a reciclagem e/ou a reutilização dos resíduos sólidos se faz necessário à implantação da coleta seletiva, onde esta é mais uma alternativa ecologicamente correta que desvia os resíduos sólidos de aterros sanitários e lixões. De acordo com a resolução $n$ ㅇ 275 do CONAMA (BRASIL, 2001), a coleta seletiva deve seguir padrões de cores para cada tipo de resíduo sólido.

O processo de realização da coleta seletiva deve ser realizado simultaneamente ao processo de sensibilização através da Educação Ambiental, pois esta é indispensável e deve ser realizada de forma continua e permanente, como está prevista na Lei 9.795/99.

Portanto, esse trabalho teve como objetivo principal analisar a disposição dos resíduos sólidos gerados na Escola de Ensino Fundamental Nossa Senhora do Rosário e a percepção ambiental entre os estudantes da Educação de Jovens e Adultos (EJA) acerca da problemática dos Resíduos Sólidos.

\section{METODOLOGIA}

A pesquisa foi desenvolvida na em um período de três meses, entre maio e julho de 2011, na Escola de Ensino Fundamental Nossa Senhora do Rosário, localizada no Bairro da Prata, em Campina Grande - PB. A referida cidade possui uma população de 383.941 habitantes (BRASIL,

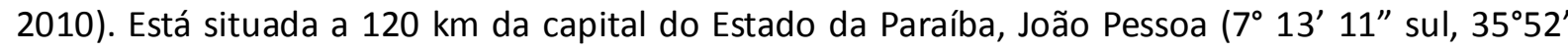
31" oeste, a 550m acima do nível do mar).

A unidade de ensino foi selecionada em decorrência de sua localização e pelo fato da mesma já dispor dos coletores para a realização da coleta seletiva nas respectivas cores: amarelo, 
verde, vermelho e azul, conforme a figura 01, porém estes se encontravam ociosos no pátio da escola já que a separação dos resíduos sólidos não estava ocorrendo de forma satisfatória, fato que remete ao entendimento de que os educandos, educadores e funcionários da unidade escolar provavelmente não conheciam e/ou não estão sensíveis da importância da coleta seletiva.
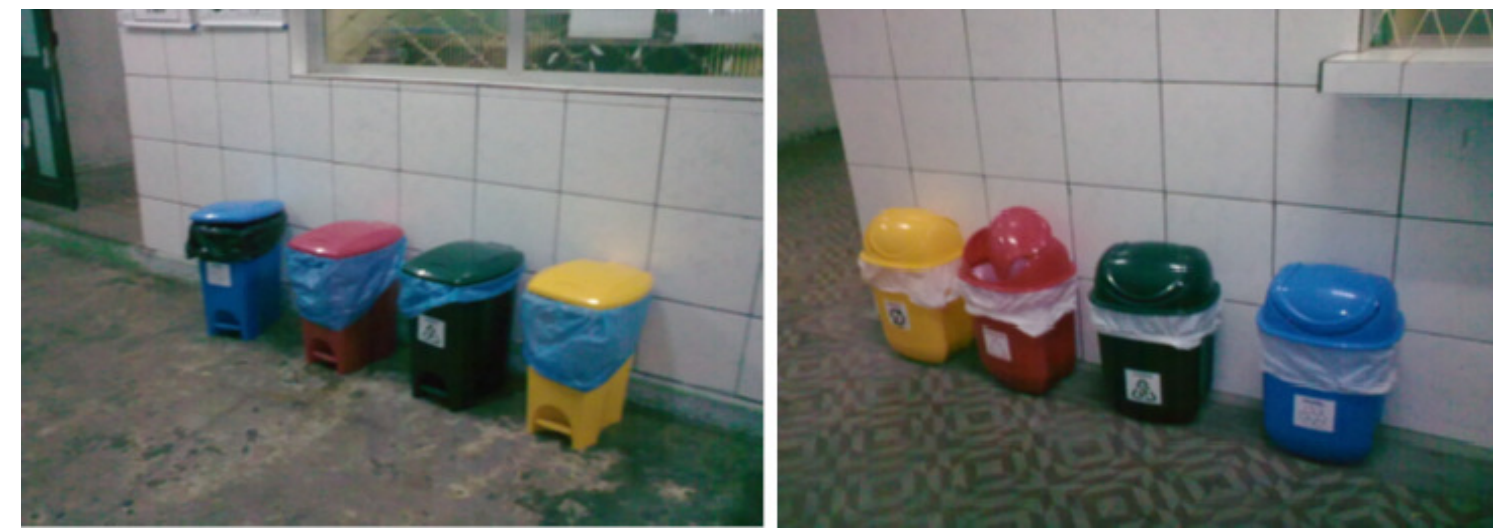

Figura 1. Coletores de materiais recicláveis disponíveis na Escola de Ensino Fundamental Nossa Senhora do Rosário. Campina Grande-PB. 2011.

Para início do trabalho foram feitas visitas diárias à unidade escolar para observação direta, objetivando identificar as formas de acondicionamento e o destino dado aos resíduos. Em seguida foram aplicados questionários semiestruturados, que forneceram a percepção ambiental dos educandos da Educação de Jovens e Adultos (EJA) sobre a problemática dos resíduos sólidos, no turno da noite dos seguintes anos: 6으, 7ㅇ e 8․ Cerca de 60 educandos responderam os questionários aplicados em sala de aula, sendo 22 educandos do sexto ano, 20 educandos do sétimo ano e 18 educandos do oitavo ano do ensino fundamental da Educação de Jovens e Adultos (EJA).

\section{RESULTADOS E DISCUSSÃO}

De acordo com os questionários aplicados, pode-se verificar que uma média de $34,6 \%$ dos estudantes da Educação de Jovens e Adultos possui uma concepção distorcida do que é resíduo sólido uma vez afirmaram que lixo e resíduos sólidos são sinônimos, no entanto é sabido que lixo é todo aquele material sem nenhuma possibilidade de reciclagem ou reutilização, que deve ser encaminhado aos aterros sanitários, e os resíduos sólidos é todo material sólido resultante das atividades diárias do homem em sociedade, que pode ser reutilizado ou reciclado, porém isso só é possível se o resíduo for selecionado na fonte geradora, o que evita a contaminação destes materiais, aumentando o seu valor agregado. A maior parte desses resíduos é composta por materiais recicláveis ou reutilizáveis e a minoria composta por lixo. No entanto, $48,7 \%$ dos estudantes da $6^{\circ}, 7^{\circ}$ e $8^{\circ}$ ano, consideraram que lixo e resíduo sólido diferiam (Figura 02). 


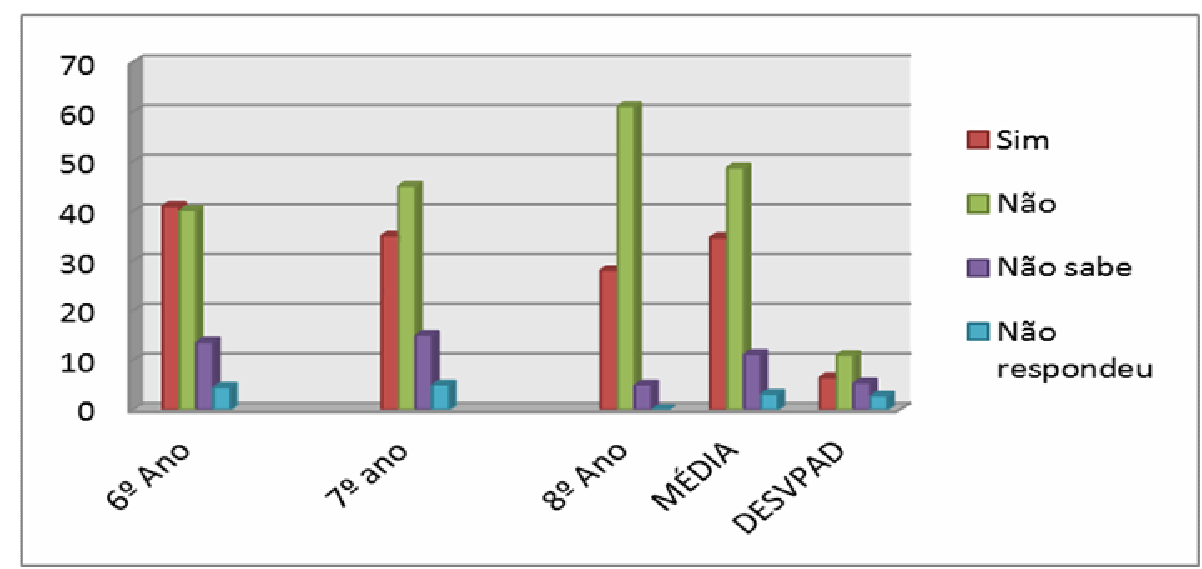

Figura 2. Percepção dos Estudantes do Ensino de Jovens e Adultos sobre a diferença entre lixo e resíduos. Campina Grande-PB. 2011.

Segundo Minc (1998), Ferreira e Anjos (2001) o lixo é todo material que não pode ser reciclado ou reutilizado, sendo descartado e na maioria das vezes encontra-se em local inapropriado, ou seja, matéria e energia fora de lugar.

De acordo com Lei 12.305 que institui a Política Nacional dos Resíduos Sólidos, no artigo 3o, inciso XVI, o resíduo sólido é considerado:

Como material, substância, objeto ou bem descartado resultante de atividades humanas em sociedade, cuja destinação final se procede, nos estados sólido ou semissólido, bem como gases contidos em recipientes e líquidos cujas particularidades tornem inviável o seu lançamento na rede pública de esgotos ou em corpos d'água, ou exijam para isso soluções técnica ou economicamente inviáveis em face da melhor tecnologia disponível (BRASIL, 2010).

Analisando os dados apresentados na figura 03, constatamos que a $49,9 \%$ dos estudantes percebem os resíduos sólidos, como sinônimo de algo que prejudica o meio ambiente e que não têm mais utilidade: "aquilo que não serve mais para consumo e é jogado fora"; "O Resíduo traz todos os problemas para nossa comunidade"; "É uma coisa que polui o ar e pode contagiar doenças". Observa-se que os estudantes em sua maioria não compreendem o conceito de resíduo sólido, até mesmo nunca tinham escutado falar sobre o assunto, uma média de $11,0 \%$ não sabe o que é um resíduo sólido, acreditando se tratar de lixo. Todavia, um percentual significativo de educandos, uma média de $21,9 \%$, percebe que os resíduos sólidos podem ser reciclados: "São embalagens de sacos, garrafas, restos de comidas e etc"; "Lixo é coisa que não se reaproveita tirando os que dá pra reciclar, como por exemplo garrafa descartável e etc" (Figura 03). 


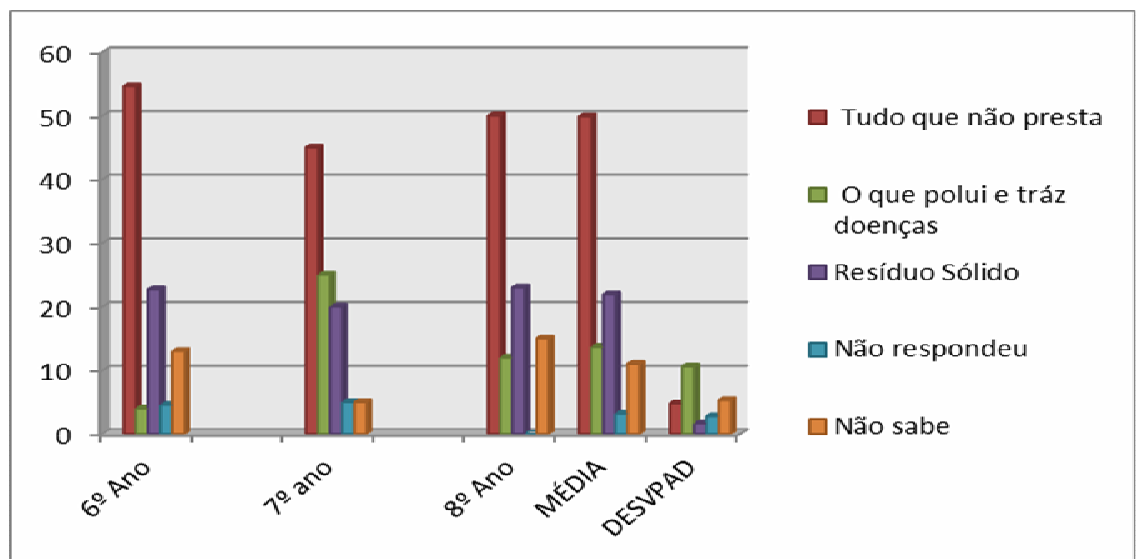

Figura 3. Concepção de Resíduo Sólido dos Estudantes do Ensino de Jovens e Adultos. Campina Grande-PB. 2011.

Os dados confirmam a visão geral que a sociedade na sua grande maioria apresenta de resíduos sólidos. Esta visão motiva à população a se livrar dos resíduos gerados de qualquer forma, não importando o destino final, inclusive não é feita a relação com os recursos naturais, ou seja, todo resíduo gerado, anteriormente constituía um recurso natural. Portanto, observa-se que é mais do que necessário implementar a Educação Ambiental no âmbito escolar, não como uma única disciplina responsabilizando o profissional das ciências naturais, mas sim, está de acordo com a Política Nacional de Educação Ambiental, a Lei 9.795/99, que afirma que a Educação Ambiental deve ser interdisciplinar atingindo todos os níveis de educação formal e informal, desse modo poderemos ter percepções ambientalmente mais sustentáveis e socialmente justas (BRASIL, 1999).

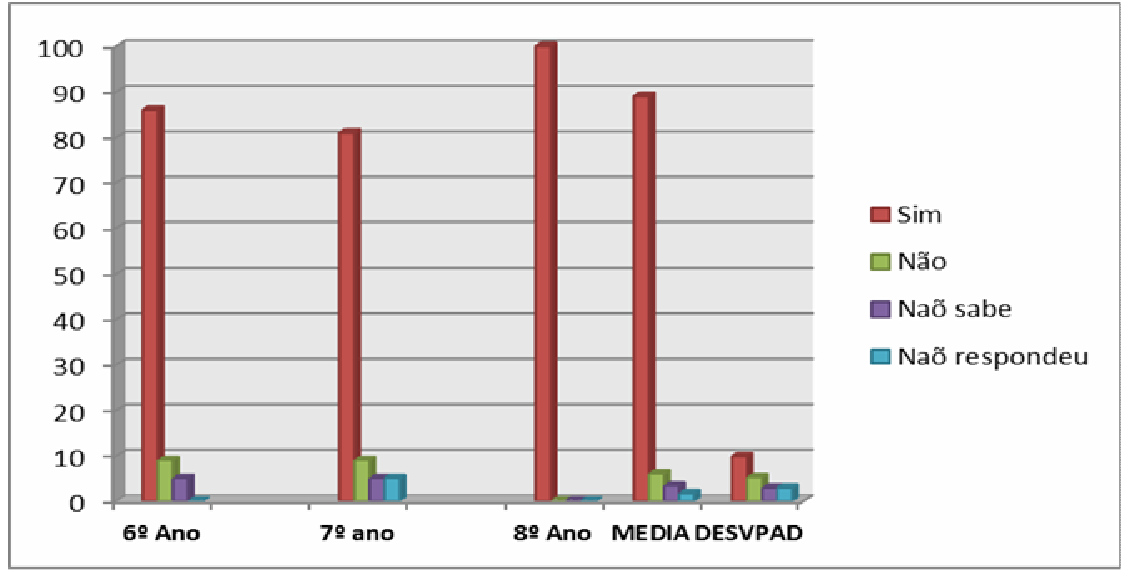

Figura 4. Concepção da utilidade dos resíduos sólidos vistos pelos estudantes do Ensino de Jovens e Adultos. Campina Grande-PB. 2011.

De acordo com a figura 05, 59,9\% dos estudantes compreendem que, existe uma relação entre lixo e meio ambiente, e que este lixo quando mal acondicionado e sem destinação adequada polui o meio ambiente trazendo diversos tipos de transtornos e impactos socioambientais, como poluição do ar, do solo e da água. No entanto $18,4 \%$ acreditam que o lixo não traz nenhum tipo de malefício ao meio ambiente, devendo ser acondicionado e descartado de qualquer forma, esse 
último dado reflete significativamente a visão antropogênica e capitalista do ser humano, no qual o paradigma social dominante tem implantado essa cultura em nossa sociedade. A Educação Ambiental almeja romper esse paradigma e a visão antropogênica, para que o ser humano passe a ter a concepção que ele também está inserido na natureza, e que os recursos naturais devem ser preservados para que as gerações futuras tenham direito a um ambiente ecologicamente equilibrado.

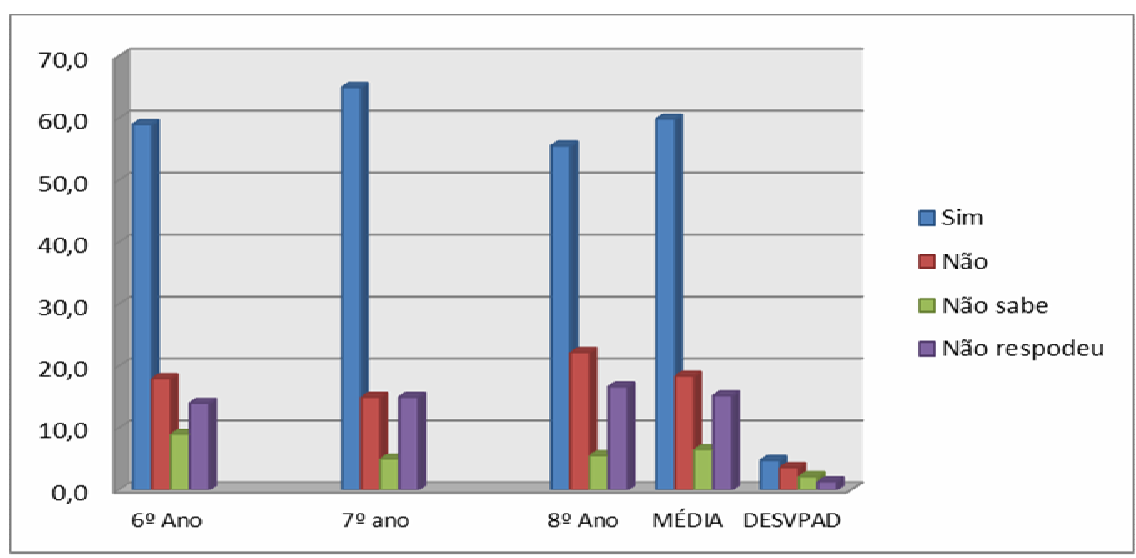

Figura 5. Percepção da relação entre lixo e meio ambiente dos Estudantes do Ensino de Jovens e Adultos. Campina Grande-PB. 2011.

O tema resíduo sólidos nunca tinha sido abordado na escola até a intervenção desse trabalho, cerca de $51,2 \%$ dos estudantes confirmaram essa problemática através dos questionários. E 24,9\% dos estudantes que afirmaram que já tinha sido abordado na escola o tema dos resíduos sólidos discutiram o assunto na disciplina de Ciências, não atendendo a Lei 9.795/99, que afirma que a Educação Ambiental deve ser interdisciplinar, abordando as questões ambientais em todas as disciplinas.

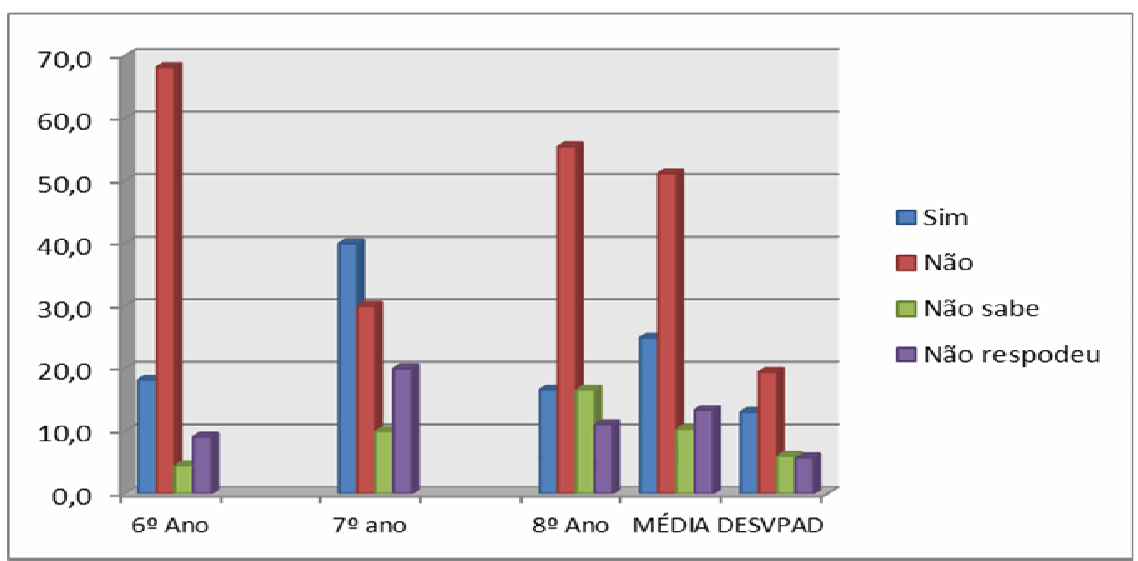

Figura 6. Abordagem da problemática dos resíduos sólidos na escola segundo os estudantes do Ensino de Jovens e Adultos. Campina Grande-PB. 2011.

Diante disso, é indiscutível o investimento na formação inicial e continuada de professores, que deve ter como base o trabalho contínuo e permanente de Educação Ambiental, como afirma a Lei $9.795 / 99$, pois, através de processos de sensibilização e a partir da percepção ambiental do grupo envolvido, permite a compreensão da complexidade do meio ambiente e o reconhecimento 
da interdependência existente entre os diversos elementos da natureza, visando a utilização racional dos recursos naturais.

\section{CONCLUSÃO}

Pode-se concluir que a educação ambiental na maioria das vezes, não foi trabalhada em sala de aula como um tema que abrange todas as disciplinas e não somente uma em específico, como institui a Política Nacional de Educação Ambiental através da lei 9.795/99, onde é mencionado no artigo $2^{\circ}$ que a educação ambiental é um componente essencial e permanente da educação nacional, devendo estar presente, de forma articulada, em todos os níveis e modalidades do processo educativo, em caráter formal e não formal. Para que assim a escola possa contribuir com parcela significativa para a formação da consciência ambiental por meio da educação formal, e que através destes educandos torna-se mais fácil atingir uma parcela maior da população. Pois os educandos podem estar repassando este conhecimento às pessoas do seu convívio familiar, através de suas ações.

$\mathrm{Na}$ identificação dos conhecimentos prévios foi possível verificar que a percepção dos educandos a respeito da temática resíduos sólidos era um tanto confusa. Os educandos sabiam que existia uma diferença entre resíduos sólidos e lixo, porém não sabiam explicar essa diferença e quando questionados sobre o que seriam resíduos sólidos os mesmos também não sabiam responder. A questão dos educandos apontar o lixo como tudo que não presta foi bastante interessante no ponto de vista que, lixo realmente é aquele material que não pode mais ser reciclado devendo ser enviando para um aterro sanitário ou lixão. No entanto, em uma das variáveis os educandos foram interrogados se o lixo teria alguma utilidade e surpreendentemente a grande maioria afirmou que sim, contradizendo que o lixo não teria mais utilidade.

Nesse contexto, Menghini (2005) entende que o objetivo da Educação Ambiental é o de "sensibilizar, provocar a reflexão das pessoas para aquilo que está a sua frente e que normalmente não se enxerga".

Portanto, pode-se concluir que o desenvolvimento deste trabalho formou cidadãos, mesmo num pequeno grupo, sensíveis e multiplicadores, embora se saiba que para haver uma mudança de hábitos e de comportamentos, é necessário um processo de Educação ambiental continuo e permanente, além de se considerar fundamental, a formação de parcerias para um melhor incentivo à comunidade e obtenção de melhores resultados, com um alcance de maior amplitude.

Após a análise dos dados obtidos e a verificação da falta de gerenciamento dos resíduos na unidade de ensino, foi promovida uma palestra sobre a problemática dos resíduos sólidos, no intuito dos educandos, educadores e funcionários conhecerem a diferença entre lixo e resíduos sólidos, lixão e aterro sanitário, enfocando a importância da coleta seletiva para a diminuição da poluição do meio ambiente e a redução da extração dos recursos naturais.

\section{REFERÊNCIAS}

BRASIL. Conselho Nacional de Meio Ambiente - CONAMA. Resolução № 275. 2001.

BRASIL, Política Nacional de Educação Ambiental. Lei 9795/99. Brasília, 1999. 
CAPRA, F. A Teia da Vida; uma nova compreensão científica dos sistemas vivos. São Paulo: Cultrix, 1996.

MENGHINI, F. B. As trilhas interpretativas como recurso pedagógico. 2005. 103p. Dissertação (Mestrado em Educação). Centro de Ciências Humanas e da Comunicação, Universidade do Vale do Itajaí, Itajaí-SC.

SILVA, M.M.P.; LEITE, V.D. Estratégias metodológicas para formação de educadores ambientais do ensino fundamental. XXVII Congresso Interamericano de Engenharia Sanitária e ambiental. Anais. Porto Alegre, 2000. 